\title{
A Method for Forecasting Potential Losses from Grasshopper Feeding on Northern Mixed Prairie Forages
}

\author{
GEORGE B. HEWITT AND JEROME A. ONSAGER
}

\begin{abstract}
Information on the potential loss of forage that might be expected from grasshopper feeding in a given season would benefit manchers and land managers if the loss could be estimated in the spring before peak forage production. A method was developed for forecasting such losses on the northern mixed prairie when most species of grasshoppers are in the 3rd and 4th instars. The method is based on the assumptions that forage losses (forage consumed + destroyed) are directly proportional to grasshopper size and density and that during the period between the 3 rd instar and death, which usually does not exceed 46 days, density decreases linearly to 0. Using feeding ratios (weight of forage destroyed/weight of adults), losses/day were calculated for each of 26 grasshopper species and for 3 groups of species separated by weight. Forecasted loss estimates for any population can be estimated if the density and species are determined, or a loss of $43 \mathrm{mg} /$ grasshopper feeding day could be used as a general average if species cannot be identified. Forecasted losses are related to grasshopper density and to observed losses at one site in Montana during a 3-year period.
\end{abstract}

Grasshoppers continue to be the most widespread and destructive pests on rangeland in the western United States. In 1979, for example, 7.2 million acres were treated by APHIS to prevent forage and crop destruction (Shannon Wilson, personal communications). Several workers have reported in the review paper by Hewitt (1977) on the effect of grasshoppers on the rangeland ecosystem. Estimates of forage losses have been determined for individual species and field populations after the losses have taken place; however, information has not been available on which to forecast losses. Forecasting is difficult because of the many highly variable interactions between an unstable environment and grasshopper development. Seasonal weather patterns directly affect the density of newly hatched nymphs in the spring and the growth and

Authors are with the Rangeland Insect Laboratory, Agriculture Research Service. U.S. Department of Agriculture, Bozeman, Montana. maturation of adults during the summer and fall when eggs are laid. Precipitation and cool weather can not only cause early instar mortality and reduced feeding, but also promote above-normal forage production that may offset the forage destroyed by grasshoppers. However, forage losses depend mainly on grasshopper density, species composition, and weather conditions from the time of hatching until death in the fall. The effect of weather on grasshopper populations cannot be predicted, but information on species and density can usually be obtained before much forage has been destroyed.

Planning for the control of grasshoppers during outbreaks or population increases would be facilitated if losses could be forecast in the spring before forage production peaked. Ranchers could use such forecasts in determining the correct stocking rates and use of rest rotation pastures. This paper describes a method of forecasting forage losses on the northern mixed prairie of the United States. Forage loss predictions are related to grasshopper density and to forage reduction in clipped plots during a 3-year period 1975-1977 in Montana. Forecasts are based on the grasshopper species present and their density when the majority of the individuals are in the 3rd and 4th instars, which is after moderation of very high levels of natural mortality that occur among earlier instars (Pick ford 1960), but is before forage losses become significant (Hewitt 1979). The proposed method for forecasting losses was developed for use by range people and extension personnel and thus an attempt was made to present a quick and efficient method that would have wide application.

\section{Methods and Materials}

Grasshoppers were collected from several locations in Montana and Wyoming over several years. For 26 species, dry weights were determined of both sexes of the 4th and 5th instars and adults. These 26 species were divided into three groups on the basis of adult dry weight (weight of sexes averaged): Group A (0-65 mg), 
Group B (66-120 mg), and Group C $>120 \mathrm{mg})$. The amount of forage destroyed (consumed + wasted) by nymphs of Camnula pellucida (Scudder) and Amphitornus coloradus (Thomas) from hatching to the adult stage was obtained from the literature (Misra and Putnam 1966). The total forage destroyed $(810 \mathrm{mg}$ ) by these two species was divided by the total adult dry weight $(179.2 \mathrm{mg})$ to obtain a nymphal feeding ratio of 4.5 . This ratio was multiplied by the average dry weight of individuals within both the 4 th and 5 th instar to give the amount of forage destroyed during the two instars by each of the 26 species (Table 1).

Information on the amount of forage destroyed on a daily basis by adults of Melanoplus sanguinipes (F.), M. infantilis Scudder, $M$. foedus Scudder, and Aulocara elliotti (Thomas) was obtained from the following sources: Parker (1930), Barnes (1955), Smith (1959), Mitchell and Pfadt (1974), Hewitt et al. (1976), Hewitt (1978), and unpublished field data. Adult feeding ratios for these species were determined by dividing the amount of forage destroyed/day by the average dry weight of the adults and then averaging the four feeding ratios to obtain an adult feeding ratio of .65 . This adult ratio (.65) was multiplied by the average dry weight of adults of the 26 species to give the forage destroyed/day by each species (Table 1).

The amount of forage destroyed by the 26 species was estimated by using 46 days as an average life span beginning with the 4th instar; 7 days were allowed for each of the last instars, and 32 days for adult life. The average loss/day was determined for each of the three groups by totaling the losses for the 4 th and 5 th instar and the adults for each species within the group. Thus, estimated average group losses per day/species were $26 \mathrm{mg}$ for those species in Group A, $49 \mathrm{mg}$ for those in Group B, and $109 \mathrm{mg}$ for those in Group C.

Density data from grasshopper populations during 1975 through 1977 near Roundup, Montana, were used to verify the forecasting method. These were the same density data that were used earlier to support a study of hatching and development in relation to forage growth, temperature, and precipitation. (Hewitt 1979). Twenty collections of grasshoppers were taken weekly along transect lines near a 1-ha exclosure; 22 such collections were made in 1975 from May 14-Oct. 6; 19 in 1976 from May 25-Sept. 28; and 16 in 1977 from May 10-Aug. 17. Collections were made by using a vacuum quick trap during the evening or after dark when tempera-

Table 1. Estimated forage loss for rangeland grasshopper species, grouped according to adult dry weight, for a 46-day period (both 4th and 5th instars last 7 days each and adults live 32 days).

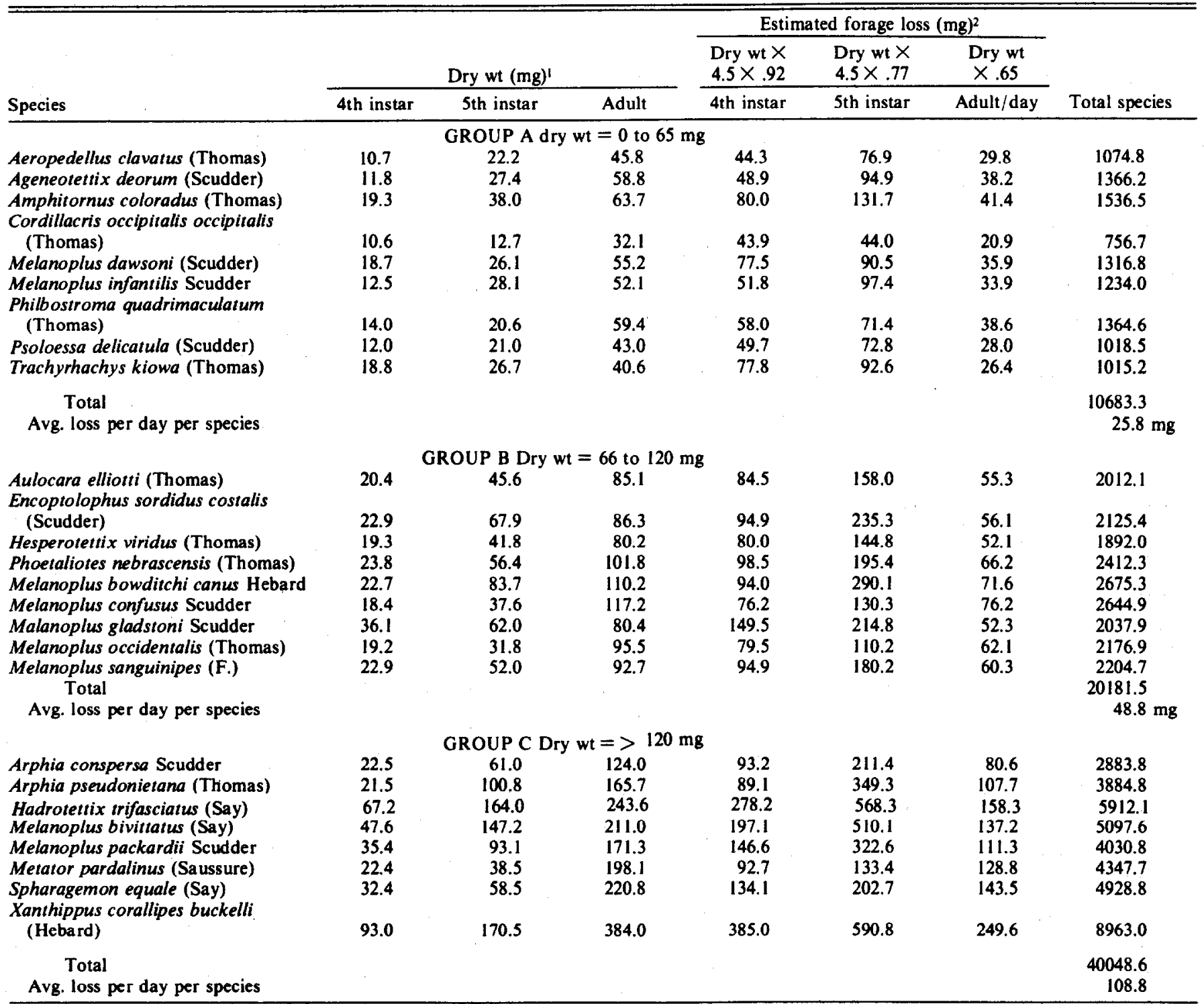

Weights are the a verages of both sexes.

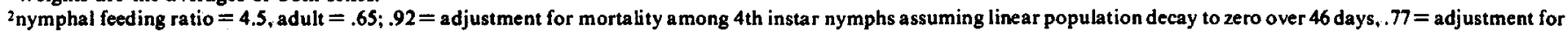
mortality among 5 th instar nymphs. 
tures were low and grasshopper activity was at a minimum. Thus, a $1 / 2-\mathrm{m}^{2}$ cage was put in place along the transect line, and trapped arthropods were vacuumed into a net placed in a $20.3-\mathrm{cm}$ diam. vacuum hose. The insects were transferred from the net into Berlese funnels at the laboratory. The number of specimens of each grasshopper species, the instar, and the sex were then determined.

Saran cages $(6 \times 6 \mathrm{~m})$ were erected within the exclosure to determine forage production and losses caused by arthropods (mainly grasshoppers). The following 4 treatments were set up, each with 3 replicates:

1. Cage effects; i.e., cages with no insects inside (methyl parathion was sprayed inside the cages when the nymphs were 2 nd and 3rd instars).

2. Grasshopper and cage effects; i.e., cages raised on blocks 10 $\mathrm{cm}$ high to allow arthropods to move in and out.

3. Grasshopper effects; i.e., plots $(6 \times 6 \mathrm{~m})$ inside the livestock exclosure with no cages but exposed to feeding by arthropods.

4. Livestock and grasshopper effects; i.e., plots (6×6 m) outside the exclosure with no cages where both livestock and arthropods were feeding.

All treatment plots were located on areas that had been mowed early in the spring to eliminate the previous year's plant growth.

Eighteen quadrats $\left(1 / 2 \mathrm{~m}^{2}\right)$ within each plot were clipped at ground level in September 1975 and August 1976 and 1977. The vegetation in each quadrat was separated into grasses, forbs, and fringed sagewort, oven-dried $\left(60^{\circ} \mathrm{C}\right)$, and weighed.

\section{Results and Discussion}

The method described for forecasting annual forage losses caused by populations of rangeland grasshoppers is based on two general assumptions:

1. Forage losses (forage consumed + wasted) are directly proportional to the average weight of individuals within each species and to their density.

2. During the time of greatest forage loss (4th and 5th instars and adult stage), the density decreases linearly to zero at the end of 25-46 days ( 14 days as nymphs and 11-32 days as adults. depending upon density).

This linear density decay rate is not valid for an entire generation of grasshoppers, but has proved to be practical for the 3rd, 4th, and 5 th instars and the adult stages (Hewitt et al. 1976, Onsager 1978). The actual length of life may vary considerably among species and years. The adult life span of Melanoplus sanguinipes, the dominant species within this study, may be greatly affected by weatherand by nutritional factors (Scharff 1961). Onsager et al. (1981) found that the average longevity of mixed populations of rangeland grasshoppers decreased as density increased. A portion of this data is reproduced her as Figure 1. Parker (1930) has shown that feeding response to temperature is linear and seasonal heat accumulation above a feeding temperature threshold of $20^{\circ} \mathrm{C}$ affects the amount of forage lost since grasshoppers feed more readily at $20^{\circ}-35^{\circ} \mathrm{C}$ than at lower temperatures. However, the method described here is based on averages and extreme deviations could cause forecasting errors. Some species hatch and develop early in the summer and others later; thus, the time when most of the grasshoppers are in the 3-4 instars varies with species and hatching temperatures at the infestation site.

Estimated daily forage losses for grasshoppers within the three groups is shown in Table 1. These losses are comparable with estimates reported by Stoliarov (1977) in Russia. He determined that daily food consumption ranged from 10 to $33 \mathrm{mg}$ for smallsized species, from 30 to $40 \mathrm{mg}$ for middle-sized species, and was ca $100 \mathrm{mg}$ for large species. By use of group averages reported in

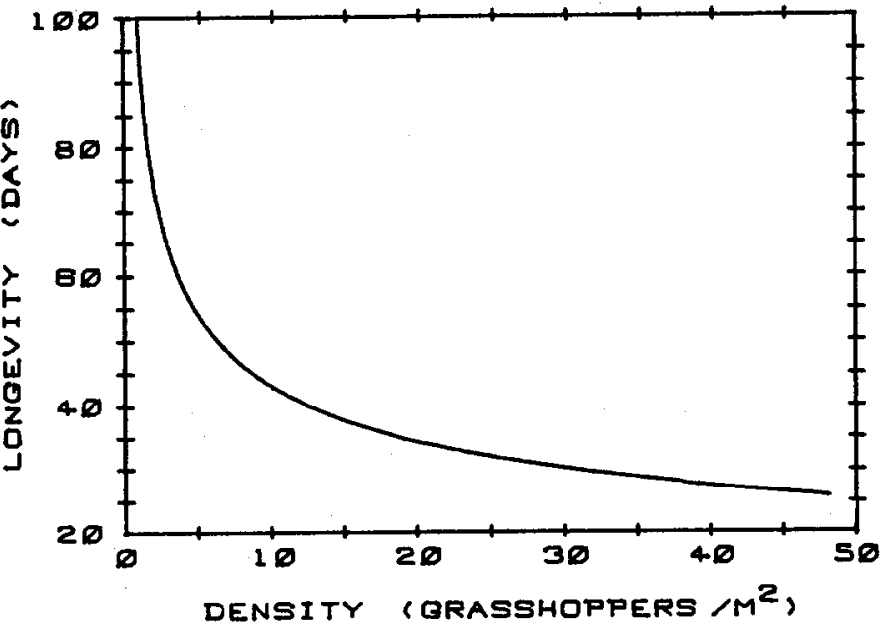

Fig. 1. Relationship between density of rangeland grasshoppers when the stage of development averaged midway between $3 \mathrm{rd}$ and $4 \mathrm{th}$ instars and average subsequent longevity at 20 sample sites on rangeland at Sheridan, Wyoming. 1980. In $\hat{Y}=4.556-0.3965(\ln X) ; p=<0.05$.

Table 1, annual losses could be forecast according to the following procedure:

1. Determine grasshopper density and species composition at the time most grasshoppers are in the 3-4 instars. Estimate density by any one of several methods (Onsager 1977) and species composition by identifying species in samples collected with a sweep net and determining the relative abundance of each.

2. Distribute the grasshoppers into the three groups according to their size and determine the density per group.

3. Determine the estimated longevity from Figure 1 and multiply that life span in days times the density. The product is "grasshopper feeding days" (GFD), per unit area.

4. Multiply the GFD by the average loss/group, which gives the forecasted forage lost per unit area $\left(\mathrm{m}^{2}\right)$ by that particular population for the growing season.

Forage losses also could be estimated when the forecaster is unable to identify the grasshopper species. Most grasshopper populations on native rangeland in Montana and Wyoming are composed of species from all of the three groups, but most individuals fall within groups $A$ and $B$.

The total number of grasshoppers collected during the 3-year period was placed in groups as follows: 2409 in Group A, 3176 in Group B, and 287 in Group C. These ratios are multiplied by the suggested loss for each group (Table 1) and the result is an average loss of $43 \mathrm{mg} /$ GFD, which is suggested for use when species cannot be identified. This figure, which is based on feeding during the 4 th and 5 th instar and adult stage, is only slightly less than the loss figure of $44.3 \mathrm{mg} /$ day that was the mean of data on forage destruction by populations of both nymphs and adults in many studies, summarized by Hewitt (1977). Putnam (1962) reported that the amount of forage destroyed/day by adults under field conditions was $53 \mathrm{mg}$ for Amphitornus coloradus (Group A) and $96 \mathrm{mg}$ for Camnula pellucida (Group B). Hewitt (1978) from tests with field cages reported that destruction by adults was $35.3 \mathrm{mg} /$ day for Melanoplus infantilis (Group A) and $60.9 \mathrm{mg} /$ day for Aulocara elliottii (Group B). These loss estimates are similar to the estimates for the three groups that include feeding by 4 th and 4 th instar nymphs.

These procedures were used to forecast potential forage losses at the Roundup site from data collected in 1975, 1976, and 1977. Results are shown in Table 2. Each year was different in terms of grasshopper density, development, plant growth, and weather conditions.

In 1975 grasshoppers began hatching on June 7 and were present 
Table 2. Forecasts of annual forage losses due to graschopper feeding near Roundup, Montana during a 3-year period, $1975-1977$.

\begin{tabular}{|c|c|c|c|c|c|c|c|c|c|c|c|c|c|}
\hline \multirow[b]{3}{*}{ Year } & \multirow{3}{*}{$\begin{array}{l}\text { Grass- } \\
\text { hopper } \\
\text { group }\end{array}$} & \multirow[b]{3}{*}{ No/ $\mathbf{M}^{2}$} & \multirow{3}{*}{$\begin{array}{c}\text { Mean } \\
\text { longevity } \\
\text { (days) }\end{array}$} & \multirow[b]{3}{*}{ GFD } & \multirow{3}{*}{$\begin{array}{c}\text { Forage } \\
\text { loss } \\
\text { GFD } \\
\text { (mg) }\end{array}$} & \multirow{2}{*}{\multicolumn{2}{|c|}{ Forecasted loss }} & \multirow{2}{*}{\multicolumn{2}{|c|}{$\begin{array}{l}\text { Expected loss based } \\
\text { on observed GFD }\end{array}$}} & \multicolumn{4}{|c|}{ Results of clipoing studies } \\
\hline & & & & & & & & & & \multicolumn{2}{|c|}{ Est. loss } & \multicolumn{2}{|c|}{ Est. reduction } \\
\hline & & & & & & $\mathrm{kg} / \mathrm{ha}$ & lb/acre & $\mathrm{kg} / \mathrm{ha}$ & $\mathrm{lb} / \mathrm{acre}$ & $\mathrm{kg} / \mathrm{ha}$ & lb/acre & $\mathrm{kg} / \mathrm{ha}$ & $\mathrm{lb} / \mathrm{acre}$ \\
\hline \multirow{5}{*}{1975} & A & 8.1 & 29 & 235 & 26 & 63 & 55 & & & & & & \\
\hline & B & 19.0 & 29 & 551 & 49 & 274 & 241 & & & & & & \\
\hline & c & 1.6 & 29 & 46 & 109 & 51 & 45 & & & & & & \\
\hline & \multicolumn{5}{|c|}{ Total } & 388 & 341 & & & & & & \\
\hline & All groups & 28.7 & 29 & 832 & 43 & 363 & 319 & 719 & 633 & 235 & 206 & 1473 & 1296 \\
\hline \multirow{5}{*}{1976} & A & 7.4 & 43 & 318 & 26 & 84 & 74 & \multirow{9}{*}{141} & \multirow{9}{*}{128} & \multirow{9}{*}{226} & \multirow{9}{*}{199} & \multirow{9}{*}{1019} & \multirow{9}{*}{897} \\
\hline & $\ddot{B}$ & 2.5 & 43 & 108 & 49 & 53 & 47 & & & & & & \\
\hline & $\mathrm{C}$ & 0.3 & 43 & 13 & 109 & 15 & 13 & & & & & & \\
\hline & & & & & Total & 152 & 134 & & & & & & \\
\hline & All groups & 10.2 & 43 & 439 & 43 & 191 & 168 & & & & & & \\
\hline \multirow{5}{*}{1977} & A & 4.8 & 46 & 221 & 26 & 58 & 51 & & & & & & \\
\hline & B & 1.6 & 46 & 74 & 49 & 36 & 32 & & & & & & \\
\hline & C & 1.5 & 46 & 69 & 109 & 76 & 67 & & & & & & \\
\hline & & & & & Total & 170 & 150 & & & & & & \\
\hline & All groups & 7.9 & 46 & 363 & 43 & 158 & 139 & 53 & 47 & 0 & 0 & 503 & 443 \\
\hline
\end{tabular}

'Forecasts made on July 17, 1975, July 8, 1976, and June 15, 1977.

'Based on species composition by group, the estimated a verage mg of forage/GFD was 46, 35, and 46 for the 3 consecutive years.

longer in the fall than in either 1976 or 1977 . They reached a peak density of $40 / \mathrm{m}^{2}$ in July. Melanoplus sanguinipes made up $53 \%$ of the population. Two forecasts of forage losses were made on July 17; one based on predicted GFD's within the three groups and one based on GFD's of the groups combined. In addition the observed GFD's are reported for the entire season based on the collections from the date of forecast to the end of the collecting period. This latter information would not normally be obtained when forage losses are forecast on a one-time basis. It should be noted the loss forecasts on July 17,1975 ( 388 and $363 \mathrm{~kg} / \mathrm{ha}$ ) are much less than the expected loss for the entire summer $(719 \mathrm{~kg} / \mathrm{ha})$. This was due to an unpredicted increase in GFD's caused by migration of late instar nymphs and adults into the study area following the initial July 17 forecast. It would also be assumed that the clipped plots would show a greater loss than $235 \mathrm{~kg} / \mathrm{ha}$. However, aboveaverage rainfall and cool temperatures (details reported by Hewitt 1979) favored plant growth and plants remained green all summer. Thus, a large part of the destroyed forage probably was replaced and the clipped plots did not give a true picture of the actual forage destroyed.

In 1976 hatching began on May 20. Densities were lower than in 1975 and Amphitornus coloradus was the most abundant species comprising $23 \%$ of the population. Forecasts made on July 8 were very similar to the loss expected for the season and to the loss estimates from the clipped plots. This year appeared to be more normal in terms of the time of grasshopper hatching and development and plant growth.

Grasshoppers began hatching on May 8 in 1977, 2-3 weeks earlier than normal. A total of 1022 Ist and 2nd instar nymphs were collected in 1977 compared with 470 in 1976 and 606 in 1975. In spite of the fact that the density on June 15 was considered noneconomical, even the low amount of predicted loss (170 and 158 $\mathrm{kg} / \mathrm{ha}$ ) did not materialize. Heavy mortality occurred among 4th and 5 th instar nymphs near the end of June due to widespread infections of the fungus disease Entomophthora grylli. The expected loss of $53 \mathrm{~kg} / \mathrm{ha}$ based on seasonal GFD's could not be measured by clipping forage samples.

It is believed that this approach to forecasting annual forage losses due to grasshoppers should be most useful to all people confronted with this problem, especially since few guidelines exist in this area of work. The method should be used as a guideline only and with the understanding that local environmental conditions may affect any forecast. A decision to control rangeland grasshoppers should always be followed with additional field observations until control is actually initiated, thus, a large increase or decrease in grasshopper density could be detected before control is attempted. Whenever grasshoppers are present, some forage loss must occur, regardless of the effect of the environment on the grasshoppers and plant development. The ultimate decision of control must be made by the rancher or land manager based on the amount of forage he can afford to lose.

\section{Literature Cited}

Barnes, O.L. 1955. Effect of food plants on the lesser migratory grasshopper. J. Econ. Entomol. 48:119-24.

Hewitt, G.B., W.H. Burleson, and J.A. Onsager. 1976. Forage losses caused by the grasshopper Aulocara elliotti on shortgrass rangeland. $J$. Range Manage. 29:376-80.

Hewitt, G.B. 1977. Review of forage losses caused by rangeland grasshoppers. USDA-ARS Misc. Pub. No. 1348, 22 p.

Hewitt, G.B. 1978. Reduction of western wheatgrass by the feeding of two rangeland grasshoppers. Aulocara ellottii and Melanoplus infantilis. J. Range Manage. 71:419-21.

Hewitt, G.B. 1979. Hatching and development of rangeland grasshoppers in relation to forage growth, temperature and precipitation. Environ. Entomol. 8:24-29.

Misra, S.D., and L.G. Putnam. 1966. The damage potential of the grasshopper, Camnula pellucida (Scudd.) (Orthoptera: Acrididae) on pastures and ranges in Canada. Indian J. Entomol. 28:224-33.

Mitchell, J.E., and R.E. Pfadt. 1974. A role of grasshoppers in a shortgrass prairie ecosystem. Environ. Entomol. 3:358-60.

Onsager, J.A. 1977. Comparison of five methods for estimating density of rangeland grasshoppers. J. Econ. Entomol. 70:187-190.

Onsager, J.A. 1978. Efficacy of carbaryl applied to different life stages of rangeland grasshoppers. J. Econ. Entomol. 71:269-273.

Onsager, J.A., N.E. Rees, and J.E. Henry, and R. Nelson Foster. 1980. Integration of bait formulations of Nosema locustae and carbaryl for control of rangeland grasshoppers. J. Econ. Entomol. 74:183-187.

Parker, J.R. 1930. Some effects of temperat ure and moisture upon Melanoplus mexicanus mexicanus Saussure and Camnula pellucida Scudder (Orthoptera). Mont. Agr. Exp. Sta. Bull. 223, 132 p.

Pickford, R. 1960. Survival, fecundity and population growth of Melanoplus bilituratus (Wlk.) (Orthoptera: Acrididae) in relation to date of hatching. Canadian Entomol. 92:1-10. 
Putnam, L.G. 1962. The damage potential of some grasshoppers (Orthoptera: Acrididae) of the native grasslands of British Columbia. Can. J. Plant Sci., Ottawa, 42:596-601.

Scharf, D.K. 1961. Ecology of the migratory grasshopper (Melanoplus bilituratus) on Montana grasslands. Ph.D thesis, Montana State Univ., Bozeman, Montana.
Smith, D.S. 1959. Utilization of food plants by the migratory grasshopper, Melanoplus bilituratus with some observations on the nutritional value of the plants. Ann. Entomol. Soc. Amer. 52:674-80.

Stoliarov, M.V. 1977. Ecological groupings of Orthoptera. Their biomass and consumption dynamics in the high mountains of the greater Caucasus in Soviet, Georgia (Rus.), Entomol. Obozr. 56:532-45. 